\title{
BMJ Open What the public knows and wants to know about medicines research and development: a survey of the general public in six European countries
}

\author{
Suzanne Parsons, ${ }^{1}$ Bella Starling, ${ }^{1}$ Christine Mullan-Jensen, ${ }^{2}$ Su-Gwan Tham, ${ }^{3}$ \\ Kay Warner, ${ }^{4}$ Kim Wever, ${ }^{5}$ on behalf of the Needs Assessment work package \\ of the European Patients' Academy on Therapeutic Innovation (EUPATI) Project
}

To cite: Parsons S, Starling B, Mullan-Jensen C, et al. What the public knows and wants to know about medicines research and development: a survey of the general public in six European countries. BMJ Open 2015;5:e006420. doi:10.1136/bmjopen-2014006420

- Prepublication history and additional material is available. To view please visit the journal (http://dx.doi.org/ 10.1136/bmjopen-2014006420).

Received 20 August 2014 Revised 6 January 2015 Accepted 7 January 2015

\section{CrossMark}

For numbered affiliations see end of article.

Correspondence to

Suzanne Parsons;

suzanne.parsons@cmft.

nhs.uk

\section{ABSTRACT}

Objectives: To explore public knowledge of, and interest in, learning more about medicines $R \& D$ in six European countries.

Design: Online survey of 6931 members of the public across Europe.

Methods: The survey formed part of a public omnibus survey. A quota sampling approach was used with quotas set according to national census data on age, gender and government region. The survey explored the public's knowledge and awareness of medicines R\&D, their interest in learning more and the perceived influences on this.

Results: The survey was completed by 6931 members of the public, over $75 \%$ of whom reported having no or less than good knowledge of medicines R\&D. Males were more likely than females to report good knowledge ( $17 \%$ vs $15 \%)$, and knowledge appeared to decrease with age. Those who were currently or had previously been involved in medical research were almost five times more likely to report good knowledge of medicines $R \& D$ overall ( $43 \%$ vs $13 \%$ ). Participants reported good knowledge of medicines safety and clinical trials but little knowledge of pharmacoeconomics. They were most interested in learning more about medicines safety and personalised and predictive medicine and least interested in pharmacoeconomics. Older people, women and respondents with current good knowledge of medicines $R \& D$ were most interested in learning more about medicines R\&D.

Conclusions: Experience of medical research appears to play a key role in increasing public awareness of and future interest in medicines R\&D. Some groups may need to be specifically targeted to increase their awareness of medicines R\&D, for example, women expressed great interest in learning more but reported less knowledge than men. It may be useful to explore further the views of those who are currently uninterested in learning more.

\section{BACKGROUND}

In recent years, the importance of involving patients and the public in their healthcare

\section{Strengths and limitations of this study}

- The survey used a robust quota sampling method which ensured that a good cross-section of the adult population in each country was covered.

- Findings are mainly generalisable to Western Europe as the only Eastern European country included was Poland.

- The survey explored participants' self-reported knowledge, and so one explanation for the low knowledge reported may be that respondents were unaware of what they did and did not know about medicines R\&D.

- Public knowledge of medicines R\&D was low but enhanced if respondents were currently or had previously been involved in medical research.

- One of the few studies conducted to explore the public's knowledge of and beliefs about medicines R\&D.

has been increasingly recognised. ${ }^{1}$ The increased accessibility of healthcare information, availability of technology and growth in self-management of health problems have led to better informed patients more willing to contribute to their care. ${ }^{2}$ Patient and public involvement (PPI) has also become increasingly undertaken within healthcare research as evidenced by the growth in accounts of PPI in the literature. ${ }^{3}$

The pharmaceutical industry has also recognised the importance of PPI in medicines R\&D and the need to make the medicines $\mathrm{R} \& \mathrm{D}$ process more patient-centred. In a recent survey, $73 \%$ of pharmaceutical industry workers believed that industry needs to change from being providers of medicines to working with patients to improve their health. In the same survey, $85 \%$ of respondents believed that the best approach to 
securing the sustainability and profitability of the pharmaceutical sector was increasing the patient centredness of its processes. ${ }^{4}$

Patients are believed to increase the usefulness and sustainability of medicines $\mathrm{R} \& \mathrm{D}$, by promoting innovation and providing new insights and solutions. ${ }^{5}$ In recent times, the pharmaceutical industry has faced a number of challenges which have highlighted the need to increase the sustainability of medicines R\&D. A key challenge has been the need to develop more complex medicines for diseases for which there is a significant unmet need. This issue has arisen partly due to the expiration of patents of a number of widely used prescription medicines. ${ }^{6}$ Therefore, medicines R\&D has become more complex and costly, with fewer new medicines being brought to market, higher prices for those that are introduced and difficulties with medicines access for some patients. ${ }^{7}$ Although increasing PPI in medicines R\&D is likely to be important to its sustainability, it is also important to note that other approaches are also likely to be beneficial, for example, working with other external stakeholders.

Little existing research has explored the public's knowledge of and interest in medicines R\&D; instead, it has focused either on the relationships between patient organisations and the pharmaceutical industry, ${ }^{8}{ }^{9}$ or on public opinion on the pharmaceutical industry's reputation. ${ }^{10}$ We identified one survey that found that consumers had little understanding of medicines R\&D and the costs involved. The study concluded that increasing public understanding of medicines R\&D may increase public trust in the pharmaceutical industry. ${ }^{11}$

As little existing research has explored public knowledge and understanding of medicines $\mathrm{R} \& \mathrm{D}$, it is likely that useful lessons may be learnt from research exploring public knowledge of clinical research, as clinical trials are an important part of medicines R\&D. A UK survey found that just $21 \%$ of the public were aware that clinical research was a core part of NHS work. ${ }^{12}$ The study concluded that low public awareness may result from a lack of good quality information on clinical research and could impact negatively on research participation and involvement. Another UK survey found that although the public were broadly aware of clinical trials, very few had detailed knowledge, and an important motivation for increasing knowledge was if they $(32 \%)$ or a family member $(46 \%)$ had been recently diagnosed with an illness. However, within this survey, $61 \%$ were interested in learning more about medicines and treatment development. Finally, within this study, a lack of public awareness and understanding of clinical trials was identified as a barrier to more active involvement. $^{13}$

The importance of increasing PPI in, and the public's knowledge of, medicines $\mathrm{R} \& \mathrm{D}$ has been recognised by the European Commission and the Innovative Medicines Initiative in their funding of the European Patients' Academy on Therapeutic Innovation (EUPATI) project between 2012 and 2017 (http://www. patientsacademy.eu). ${ }^{14}$ EUPATI aims to increase PPI in and public knowledge and understanding of medicines R\&D across Europe. EUPATI is a consortium project, led by the European Patients' Forum, with 30 project partners across Europe from patient organisations, academic institutions and pharmaceutical companies.

EUPATI aims to increase public knowledge and understanding of medicines R\&D (1) to help the public communicate more effectively with health professionals about new medicines; (2) to increase public understanding of the decisions made regarding the cost and availability of new medicines; and (3) to increase public knowledge and awareness of medicines R\&D to facilitate future active involvement.

To fulfil its aims, EUPATI is developing a training course which aims to increase patient experts' capacity to become actively involved in medicines $\mathrm{R} \& \mathrm{D}$, a toolkit for patient advocates to facilitate dissemination of medicines R\&D information to patients, and an online library of medicines R\&D information for the public.

A key element of EUPATI has been a programme of social research exploring patients' and the public's information needs and beliefs regarding medicines R\&D, the findings from which have informed the development of the education and training materials. The survey reported here forms an important part of this work. The survey was conducted in six European countries to explore the views of Europeans about these issues.

\section{AIMS AND OBJECTIVES}

To explore within Great Britain (GB), France, Spain, Italy, Poland and Germany:

1. The public's knowledge of and interest in learning more about medicines R\&D;

2. How knowledge and interest varies by demographic factors, country and current or previous involvement in medical research.

\section{DESIGN AND METHODS}

\section{Survey administration}

An online survey of the public was conducted in GB, France, Germany, Italy, Spain and Poland. These countries were selected as they represent the six most widely spoken mother tongues in Europe. ${ }^{15}$

The survey was administered as part of an omnibus survey in each country. An omnibus survey is a survey design where data on a wide variety of topics are collected using the same questionnaire. Therefore, participants answer questions that have been added by a range of different organisations and on a range of different topics. The organisations then share the common demographic data from the survey. ${ }^{16}$

\section{Sampling}

Survey participants were recruited from online research panels maintained by ICM Research in each country. 
The panels consist of adults aged 18-64 years (18-65 plus in GB) who have given their explicit permission to be contacted about surveys. The size of the research panels ranges from 1.4 million to 33000 people. Panel recruitment is constant to ensure that panels are representative of the demographics of the relevant countries. Panellists are recruited using a range of online and offline methods, for example, postal invitations and email and advertising campaigns are run periodically to target hard-to-reach groups.

A quota sampling approach was used to identify participants, with quotas being set according to national census data on age, gender and government region of each country surveyed. The final data set was weighted according to these factors to enable the study to be considered representative of the internet-using participants of 18-64 years living in these countries.

Respondents were selected using their profile criteria and the quotas that had been set for the project and then contacted by email. After the quotas and required sample size were reached, the survey was closed. The quota for all countries was 1000 apart from GB, where it was 2000. This was due to the needs of other research clients contributing questions to the GB omnibus.

\section{Questionnaire development and translation}

The questionnaire was developed by brainstorming within the research team, reference to existing research literature and by collaboration with related EUPATI work programmes. The questionnaire was then tested with five volunteers using cognitive interviewing. ${ }^{17}$ This involved exploring if questions were interpreted as intended and highlighted any repetition or the need for further explanations. The questionnaire was modified following this process and the final version was forward translated into the relevant languages from English by ICM Research (see online supplementary data 1). A back-translation check was undertaken by the translation support within the EUPATI consortium.

The questionnaire began with a preamble to the study and to EUPATI. Respondents were given the option to opt out of the survey if they wished. The questionnaire covered (1) current or previous involvement in medical research; (2) knowledge of medicines R\&D; (3) interest in learning more about medicines $\mathrm{R} \& \mathrm{D}$ and (4) preferences for information sources and channels.

\section{DATA ANALYSIS}

Data were managed and analysed using EXCEL and SPSS. Cronbach's $\alpha$ was calculated for the questionnaire items. $^{18}$

Respondent characteristics-The characteristics of respondents were described (age, gender and involvement in medical research) and the relationships between these factors were explored using unadjusted ORs, Cochran-Mantel-Haenszel $\chi^{2}$ tests and $p$ values.

\section{Current knowledge of and interest in learning more about} medicines R\&D

Respondents' reported knowledge of and interest in learning more about medicines R\&D overall and of a range of aspects of medicines $\mathrm{R} \& \mathrm{D}$ was explored. Current knowledge of and interest in learning more about aspects of medicines $\mathrm{R} \& \mathrm{D}$ was ranked according to the percentage of respondents who reported good/ very good knowledge of a particular area. When percentages were identical, they were assigned the same rank several times and the next lower rankings were skipped. When comparing responses by country, the over $65 \mathrm{~s}$ were removed from the analysis as they were only included in GB. Knowledge of and interest in learning more about each aspect of medicines R\&D was compared across countries using Pearson's $\chi^{2}$ tests.

We used a relatively simple approach to ranking the data, as currently little is known about the public's knowledge of medicines $\mathrm{R} \& \mathrm{D}$, and so we felt that ranking the individual areas of medicines $\mathrm{R} \& \mathrm{D}$ within each country would be the most informative approach and in line with the aims of this study. We appreciate that there are other approaches to ranking which involve developing rankings on the basis of a number of variables, ${ }^{19}{ }^{20}$ but such rankings are likely to be influenced by the choice of variables used to develop the indicator.

Unadjusted ORs, Cochran-Mantel-Haenszel $\chi^{2}$ tests and $\mathrm{p}$ values and multivariate analysis (logistic regression) were used to explore the relationships between (1) current overall knowledge of medicines R\&D and age, gender and experience of medical research, and (2) future interest in learning more about a range of aspects of medicines R\&D and age, gender and previous experience of medical research. Multivariate analysis was also undertaken to explore the relationship between interest in learning more about medicines safety and age, gender, previous experience of medical research and having good current overall knowledge of medicines $\mathrm{R} \& D$.

\section{RESULTS}

In total, 6931 members of the public completed the questionnaire. There were no exclusions due to missing data, and so the data included in this analysis were complete. The quota of 2000 respondents was not reached in GB due to the required closure date for the survey in $\mathrm{GB}$, which was an operational issue for ICM.

Cronbach's $\alpha$ was calculated for two nine-item scales within the questionnaire: (1) knowledge and (2) interest in learning more about medicines R\&D.

Cronbach's $\alpha$ for both scales was 0.95 , indicating that each scale had a high degree of internal consistency.

\section{Demographic characteristics of the sample}

The age profile of survey respondents was broadly representative of the age profiles of the countries studied, for 
example, a smaller percentage of participants of 18-24 years compared with other groups ${ }^{21}$ (table 1 ). Just $6 \%$ of respondents were over 65 as this age group was just included in GB. There was an equal distribution of men and women.

\section{Current or previous involvement in medical research}

Current or previous involvement in medical research ranged from $8 \%$ to $10 \%$ across all countries apart from Germany, where it was $4 \%$ (table 1). The difference between countries regarding medical research involvement was significant at the $1 \%$ level $\left(\chi^{2}=45.0 ; \mathrm{df}=5\right.$; $\mathrm{p}<0.001)$.

Current or previous involvement in medical research appeared to decrease with age, with participants of 18-24 and 25-34 years being most likely to report involvement (20\% and 24\%, respectively). Men were more likely than women to report current or previous involvement ( $58 \%$ vs $42 \%$, OR=1.51, CI 1.27 to 1.80 ; see online supplementary data 2 ).

\section{Current knowledge of medicines R\&D}

Respondents' current overall knowledge of medicines $\mathrm{R} \& \mathrm{D}$ and its specific aspects was ranked according to the percentage of respondents reporting good/very good knowledge of each aspect (table 2). Respondents ranked their knowledge of medicines safety highest in all countries apart from France, where it ranked third. Knowledge of clinical trials was also highly ranked in all countries (1st, 2nd or 3rd) apart from Spain, where it ranked seventh. Finally, the lowest ranked area was pharmacoeconomics (ranked 8th, 9th or 10th in all countries).

For all aspects of medicines $\mathrm{R} \& \mathrm{D}$, the differences between countries in the percentage of respondents reporting good/very good knowledge was significant at the $5 \%$ level.

However, it is important to note that the percentage of respondents reporting good/very good knowledge of medicines R\&D was relatively low, ranging from $30 \%$ for medicines safety in Italy to a minimum of $11 \%$ for pharmacoeconomics in Poland.

\section{Demographic influences on overall medicines R\&D knowledge}

Gender

Just 17\% (590/3385) of men and 15\% (542/3546) of women reported good knowledge of medicines R\&D overall ( $\mathrm{OR}=1.17$, CI 1.03 to 1.33 ; table 3$)$. Over threequarters of men and women reported less than good knowledge of medicines R\&D.

Age

Over three-quarters of all age groups reported less than good knowledge of medicines R\&D overall, but as age increased, reported knowledge appeared to decrease from $19 \%$ in those aged $18-24$ years to $11 \%$ in those aged 65 years and older $(\mathrm{OR}=0.54$, CI 0.38 to 0.76$)$.

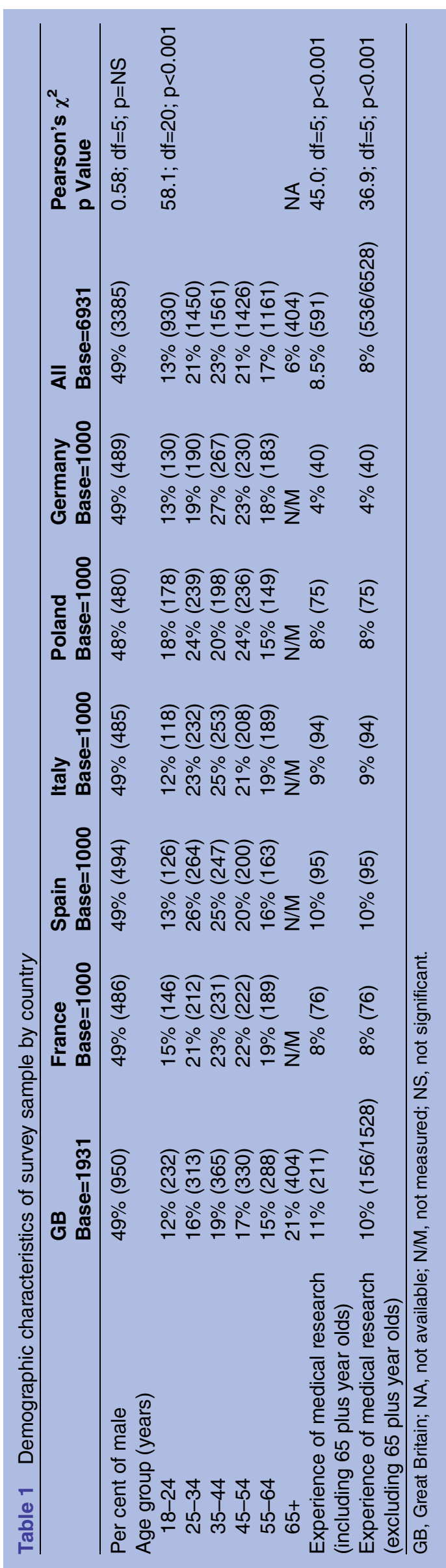




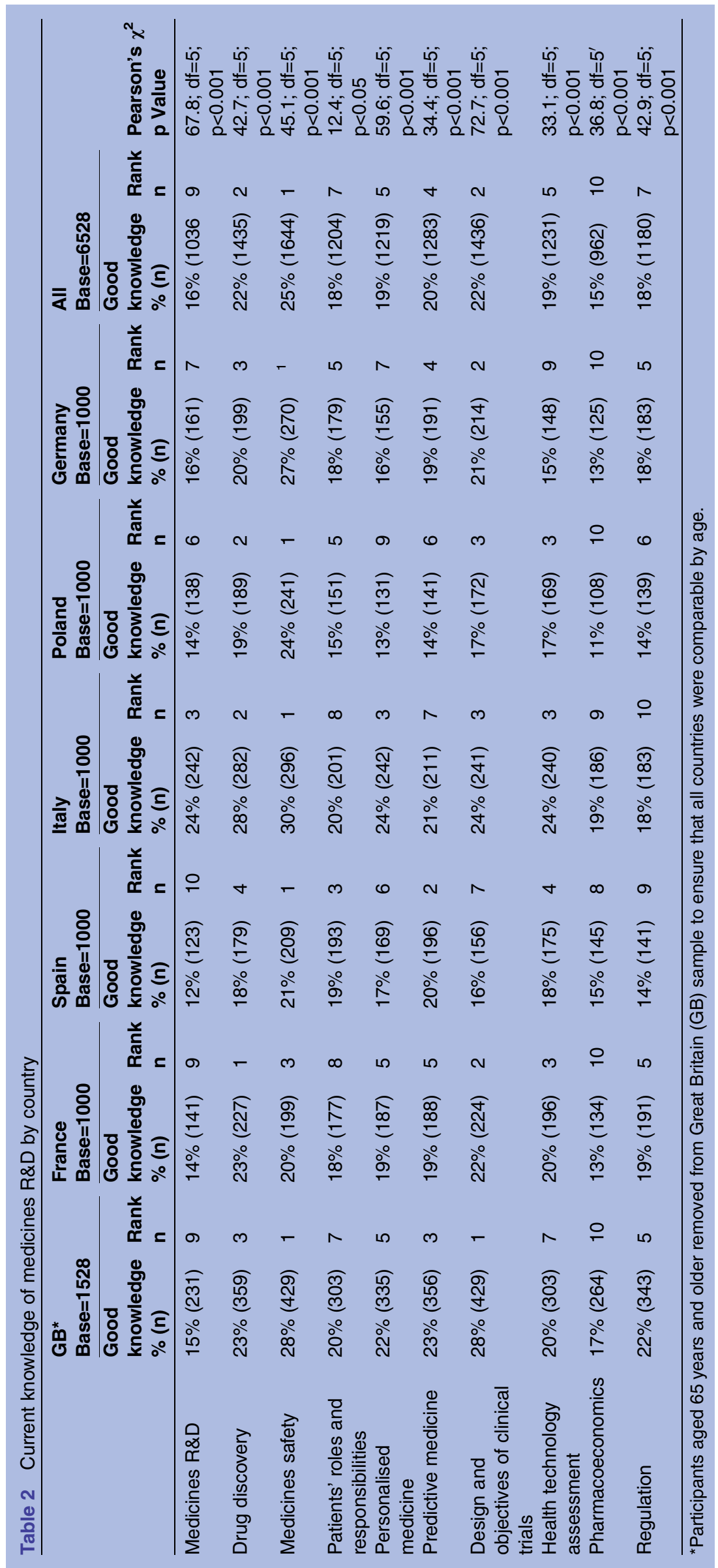


Table 3 Relationship between demographic factors and experience of research involvement on reported knowledge of medicines R\&D

\begin{tabular}{|c|c|c|c|c|}
\hline & $\begin{array}{l}\text { No or less than } \\
\text { good knowledge }\end{array}$ & $\begin{array}{l}\text { Good or very } \\
\text { good knowledge }\end{array}$ & $\begin{array}{l}\text { Mantel-Haenszel } \chi^{2} \\
\text { p Value }\end{array}$ & OR (95\% Cl) \\
\hline Overall (N=6931) & $84 \%(5800)$ & $16 \%(1131)$ & NA & NA \\
\hline \multicolumn{5}{|l|}{ Gender } \\
\hline Female $(\mathrm{N}=3546)$ & $85 \%(3005)$ & $15 \%(541)$ & $5.68 ; d f=1 ; p<0.05$ & 1.0 \\
\hline Male $(\mathrm{N}=3385)$ & $83 \%(2796)$ & $17 \%(589)$ & & $1.17(1.03$ to 1.33$)$ \\
\hline \multicolumn{5}{|l|}{ Age (years) } \\
\hline $18-24(\mathrm{~N}=930)$ & $81 \%(751)$ & $19 \%(179)$ & & 1.0 \\
\hline $25-34(N=1450)$ & $81 \%(1175)$ & $19 \%(275)$ & $0.03 ; d f=1 ; p=N S$ & $0.98(0.80$ to 1.21$)$ \\
\hline $35-44(\mathrm{~N}=1561)$ & $85 \%(1322)$ & $15 \%(240)$ & $6.3 ; d f=1 ; p<0.05$ & 0.76 (0.61 to 0.95$)$ \\
\hline $45-54(N=1426)$ & $85 \%(1214)$ & $15 \%(213)$ & $7.6 ; d f=1 ; p<0.01$ & 0.74 (0.59 to 0.92$)$ \\
\hline $55-64(\mathrm{~N}=1161)$ & $85 \%(982)$ & $16 \%(180)$ & $5.1 ; d f=1 ; p<0.05$ & 0.77 (0.61 to 0.97$)$ \\
\hline 65 and over $(\mathrm{N}=404)$ & $89 \%(358)$ & $11 \%(46)$ & $12.4 ; d f=1 ; p<0.0001$ & 0.54 (0.38 to 0.77$)$ \\
\hline \multicolumn{5}{|c|}{ Previous research participation } \\
\hline $\mathrm{No}=6358$ & $86 \%(5480)$ & $14 \%(877)$ & & 1.0 \\
\hline Yes $=573$ & $56 \%(319)$ & $44 \%(253)$ & $355 ; d f=1 ; p<0.001$ & 4.97 (4.14 to 5.99$)$ \\
\hline
\end{tabular}

Relationship between reported knowledge of medicines R\&D and experience of medical research involvement

Those with current or previous experience of medical research were almost five times more likely to report good overall knowledge of medicines R\&D than those without previous experience ( $43 \%$ vs $13 \%$, OR $=4.97$, CI 4.16 to 5.96 ; table 3 ).

In multivariate analysis, the most significant predictor of reporting good/very good knowledge of medicines $\mathrm{R} \& \mathrm{D}$ was experience of medical research, with those with experience being approximately five times more likely to report good/very good knowledge than those without. Older age was related to being less likely to report good/very good current knowledge of medicines $\mathrm{R} \& \mathrm{D}$. However, the $\mathrm{R}^{2}$ was just 0.04 , suggesting that the included variables explained a low percentage of the variance (see online supplementary data 4 ).

\section{Interest in learning more about particular areas of medicines R\&D}

Across the whole sample, respondents expressed the greatest interest in learning more about medicines safety (49\%) and personalised and predictive medicine $(47 \%$; table 4).

Respondents' reported interest in learning more about aspects of medicines R\&D was ranked and compared within and across countries. Interest in learning more ranged from 29\% (pharmacoeconomics-GB and France) to $58 \%$ (medicines safety-Italy).

Medicines safety was ranked first in all countries apart from GB, where it was ranked third. Respondents also reported high levels of interest in personalised and predictive medicine (ranked first to fifth in all countries) and the lowest levels of interest in learning more about pharmacoeconomics (ranked 9th in all countries).

For all aspects of medicines R\&D, the difference between countries in the percentage of respondents interested in learning more about each aspect was significant at the $5 \%$ level.

Interest in learning more about medicines R\&D: demographic influences

Age

There were significant differences between age group and interest in learning more about all aspects of medicines R\&D (see online supplementary data 3). Those aged 65 years and older were most interested in learning more about medicines safety (54\%), patients' roles and responsibilities $(54 \%)$, personalised and predictive medicine $(51 \%)$ and regulation $(41 \%)$. Younger people appeared to be more interested in personalised and predictive medicine $(46 \%$; see online supplementary data 3$)$.

\section{Gender}

Women expressed greater interest in learning more about all aspects of medicines R\&D than men (figure 1). This difference was significant for all aspects. However, the areas of interest for men and women followed the same pattern with both being most interested in learning more about medicines safety and least interested in pharmacoeconomics.

\section{Interest in learning more about medicines R\&D- influence of experience of medical research}

Previous or current involvement in medical research was related to greater interest in learning more about all aspects of medicines R\&D (figure 2), with those with experience of medical research being around twice as likely to be interested in learning more about all aspects of medicines R\&D than those without experience.

As medicines safety was the area of medicines $\mathrm{R} \& \mathrm{D}$ that respondents were most interested in learning more about, the relationship between interest in learning more about medicines safety and gender, age, 


\section{Interest in learning more about aspects of medicine}

$R \& D$ by gender

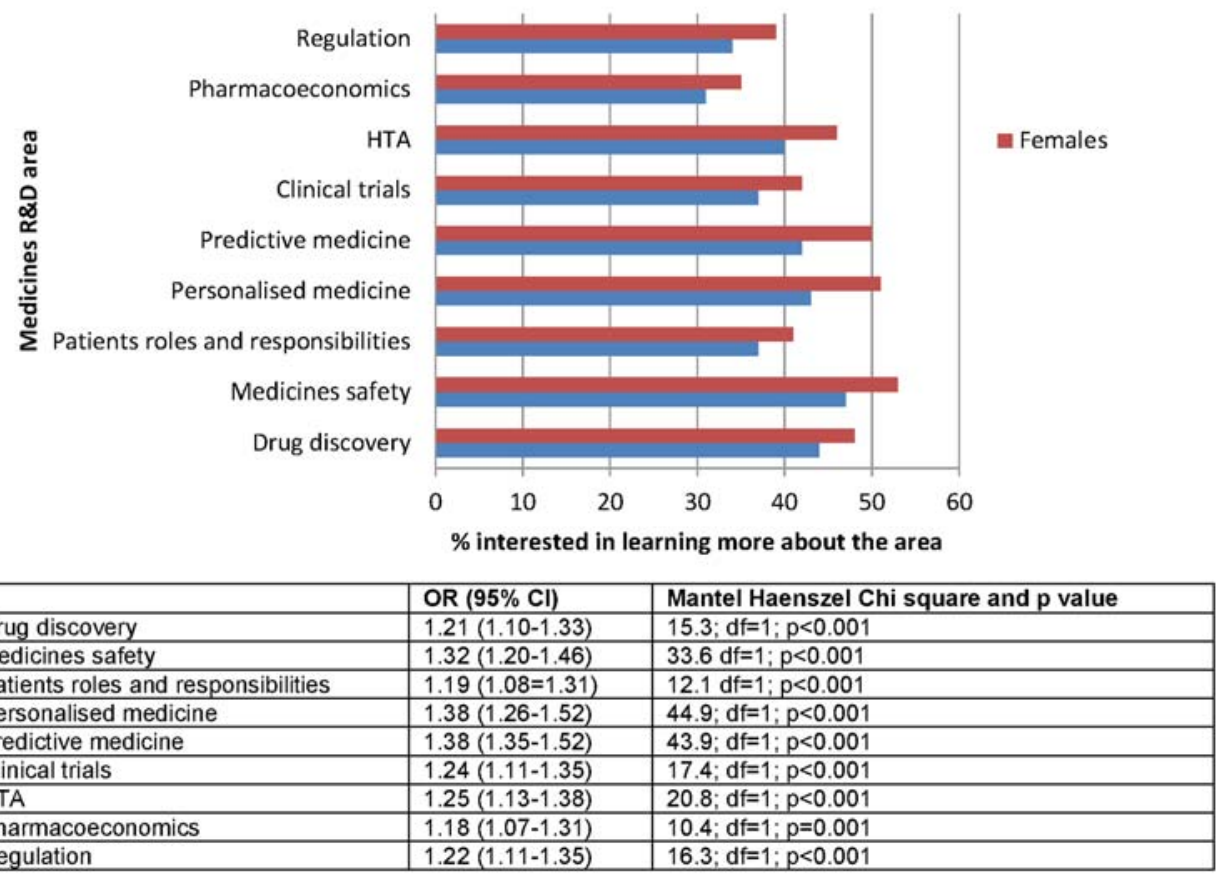

Figure 1 Relationship between interest in learning more about medicines R\&D and gender, N=6931 (HTA, health technology assessment).

experience of medical research and current knowledge of medicines R\&D was explored.

For all age groups, reporting good/very good current knowledge of medicines R\&D was a significant predictor of being interested in learning more about medicines safety. Those reporting good/very good knowledge were approximately four times more likely to be interested in learning more about medicines safety. Younger age groups and men were less likely to be interested in learning more about medicines safety.

When other variables were taken into account, previous experience of medical research was not a significant predictor of future interest in learning more, although those with previous experience were slightly more likely to express interest in learning more about medicines safety (see online supplementary data 5 ).

\section{DISCUSSION}

Reported knowledge of medicines R\&D was low with over three-quarters of respondents reporting less than good overall knowledge of medicines R\&D (table 3). Knowledge was similarly low when specific aspects of medicines R\&D were considered, with at most $30 \%$ reporting good knowledge of any area (medicines safety in Italy; table 2).

One explanation for respondents' low knowledge may have been that the survey explored self-reported knowledge, and so respondents may have been unaware of their true knowledge levels. Perhaps if other research methods had been used to explore knowledge, for example, qualitative methods, then respondents may have described greater knowledge. Another explanation could be that this was a survey of the general public, and so many respondents were likely to be well and less interested in clinical research. ${ }^{13}$ Finally, the low knowledge reported may reflect a lack of existing high-quality information for the public on medicines R\&D.

In all countries, respondents reported the greatest knowledge of medicines safety, drug discovery and clinical trials, and the least knowledge of pharmacoeconomics and regulation (table 2). This may indicate the extent to which these topic areas are currently discussed in the media. Respondents may report more knowledge of medicines safety as they may believe it to be more personally relevant, for example, if they are taking medication, and of clinical trials as this may be the aspect of medicines R\&D that they are most familiar with, albeit from few high-profile trials with controversial results. ${ }^{22}$ Respondents may have reported less knowledge of pharmacoeconomics and regulation as in the past these areas may have been poorly communicated to the public, although efforts are now being made to improve communication and involve patients more in regulation. ${ }^{23}$

As described earlier, PPI in medicines R\&D is becoming increasingly important; however, the percentage of respondents reporting good knowledge of patients' roles and responsibilities within medicines $\mathrm{R} \& \mathrm{D}$ was low at 15-20\% (table 2). One explanation for this may be the low levels of research experience reported by respondents, that is, experience of participation in clinical trials may increase the public's knowledge of clinical 
Figure 2 Relationship between interest in learning more about medicines $R \& D$ and previous experience of medical research, $\mathrm{N}=6931$ (HTA, health technology assessment).

Interest in learning more about aspects of medicines R\&D by previous experience of medical research

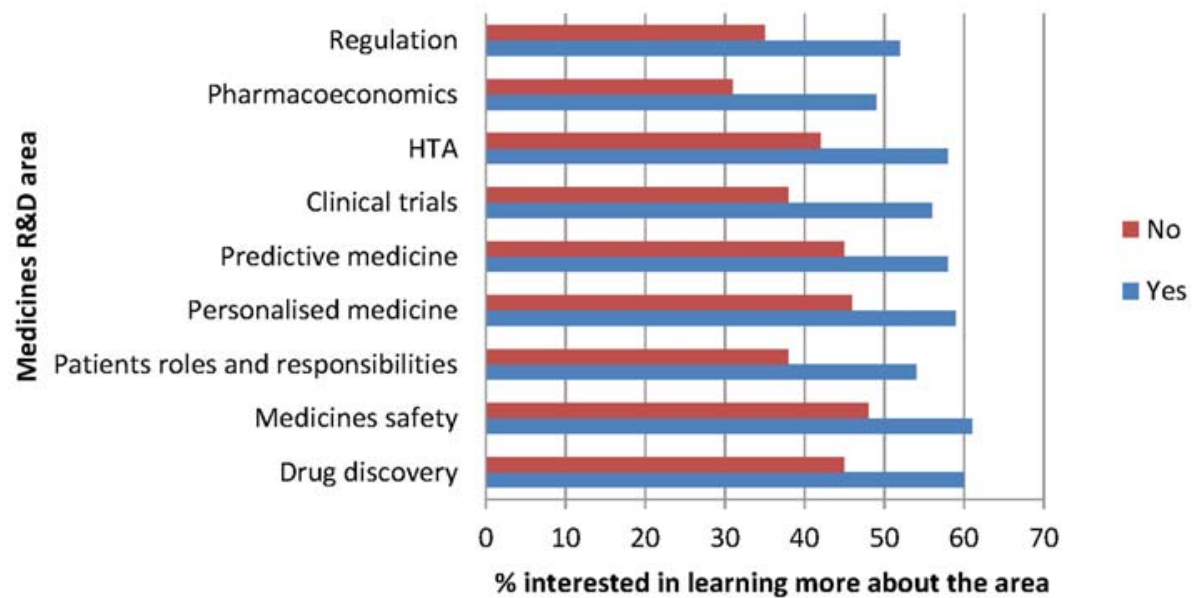

\begin{tabular}{|l|l|l|}
\hline & OR $(95 \% \mathrm{Cl})$ & $\begin{array}{l}\text { Mantel Haenszel Chi square and } \mathbf{p} \\
\text { value }\end{array}$ \\
\hline Drug discovery & $1.83(1.54-2.18)$ & $47.5 ; \mathrm{df}=1 ; \mathrm{p}<0.001$ \\
\hline Medicines safety & $1.60(1.39-1.98)$ & $32.7 ; \mathrm{df}=1 ; \mathrm{p}<0.001$ \\
\hline Patients roles and responsibilities & $1.90(1.63-2.13)$ & $58.2 ; \mathrm{df}=1 ; \mathrm{p}<0.01$ \\
\hline Personalised medicine & $1.69(1.41-2.00)$ & $35.3 ; \mathrm{df}=1 ; \mathrm{p}<0.001$ \\
\hline Predictive medicine & $1.74(1.45-2.07)$ & $39.6 ; \mathrm{df}=1 ; \mathrm{p}<0.001$ \\
\hline Clinical trials & $2.11(1.78-2.50)$ & $75.0 ; \mathrm{df}=1 ; \mathrm{p}<0.001$ \\
\hline HTA & $1.93(1.62-2.30)$ & $56.6 ; \mathrm{df}=1 ; \mathrm{p}<0.001$ \\
\hline Pharmacoeconomics & $2.13(1.80-2.50)$ & $77.3 ; \mathrm{df}=1 ; \mathrm{p}<0.001$ \\
\hline Regulation & $1.98(1.67-2.350$ & $62.3 ; \mathrm{df}=1 ; \mathrm{p}<0.001$ \\
\hline
\end{tabular}

trial processes. ${ }^{24}$ It may also reflect a lack of interest discussed earlier. Finally, although there are a number of good examples of patient involvement in medicines $\mathrm{R} \& \mathrm{D}$, for example, HIV and rare diseases, it is reasonable to say that patient involvement is currently not widespread or well communicated within the pharmaceutical industry. ${ }^{25}$ Therefore, the wider public may be unaware that patients and the public can become involved in medicines R\&D.

When considering increasing public knowledge of medicines $\mathrm{R} \& \mathrm{D}$, it may be important to consider that the public's previous experience of medical research appears to be related to both their current knowledge and interest in learning more (table 3 and figure 2). Further qualitative work to explore this may be useful.

\section{Influence of age, gender and experience of medical} research on overall knowledge of medicines $R \& D$

Young people and men reported greater overall knowledge of medicines R\&D (table 3). This may be because these groups are more likely to have previously participated in medical research, and their previous experience may have increased their confidence in their knowledge. ${ }^{24}$ Older people and women were less likely to report good knowledge, which may be a by-product of the long-standing under-representation of these groups in medical research. ${ }^{26} 27$

\section{Interest in learning more about medicines R\&D}

Interest in learning more about specific aspects of medicines R\&D ranged from $49 \%$ (medicines safety) to $33 \%$ (pharmacoeconomics; table 4). In all countries, respondents were most interested in learning more about medicines safety, personalised and predictive medicine and drug discovery, and least interested in pharmacoeconomics and regulation.

There were limits to the public's interest in learning more about medicines R\&D, which may need to be taken into account when developing public information, or when considering how to stimulate interest in this area.

Interest in medicines safety may reflect concern about side effects and that all members of the sample are likely to have taken medicines at some point. Interest in personalised and predictive medicine may reflect the recent expansion of press and television coverage of these areas or, in the case of this survey, reports of Angelina Jolie's healthcare decision regarding her genetic risk of breast cancer may have raised awareness, as this was a prominent story at the time this survey was administered (May/June 2013). ${ }^{28}$

Respondents reported fairly low levels of interest in learning more about clinical trials (table 4). This may be because they felt that they had enough knowledge about clinical trials already. However, for some members of the public, their exposure to clinical trials information may primarily come from negative media stories which may have influenced their willingness and interest to learn more. ${ }^{22}$ Finally, it may also reflect the general population nature of this survey, as many respondents were likely to be healthy and perhaps unlikely to consider it important to learn more about clinical trials. 


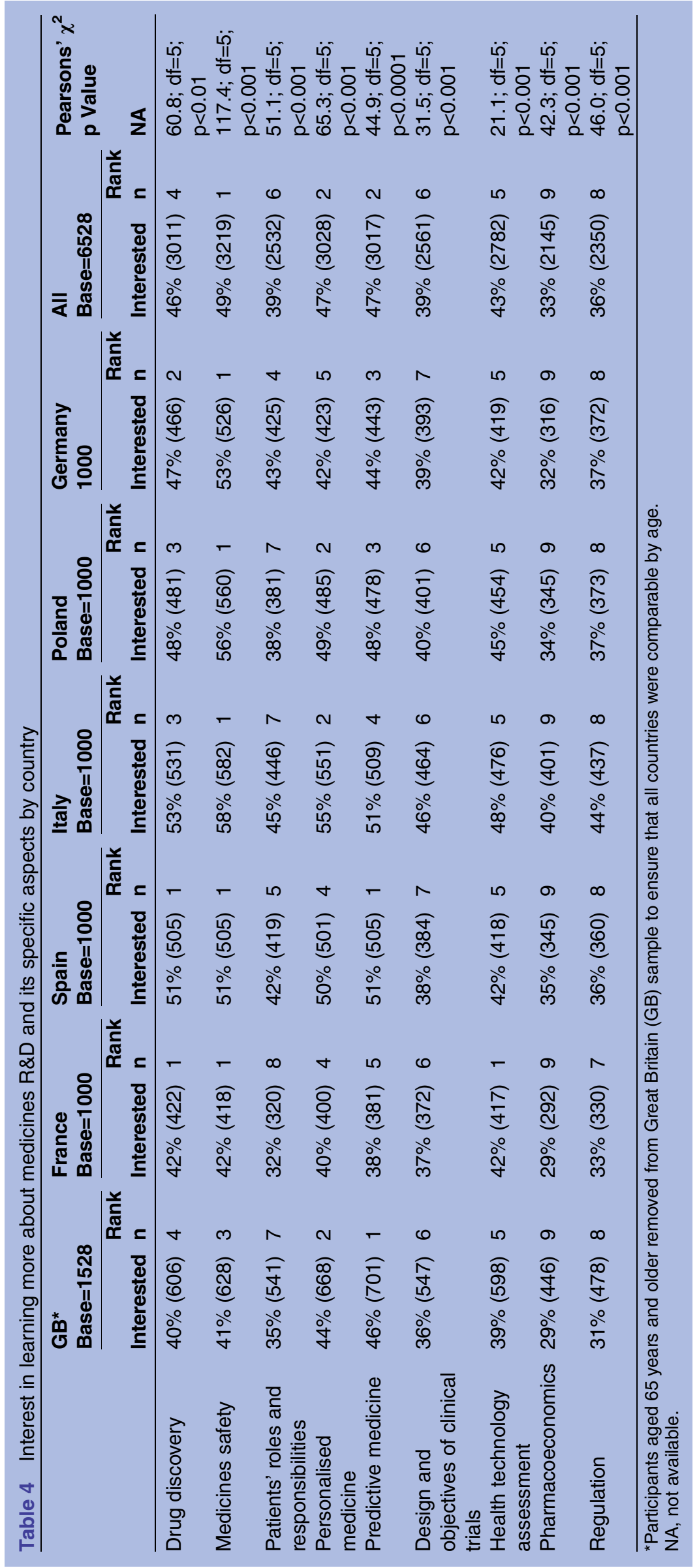


Influence of age, gender and experience of medical research on interest in learning more about medicines $R \& D$

In univariate analysis, women and older people expressed the greatest interest in learning more about medicines R\&D, despite, or perhaps because, they also reported the lowest knowledge levels (see online supplementary data 3 and figure S1). These findings may also reflect a greater interest, contact and familiarity with healthcare among these groups. ${ }^{29}$ Conversely, despite being more confident of their knowledge of medicines $\mathrm{R} \& \mathrm{D}$, men and younger people expressed less interest in learning more. They may have felt that they had gained enough knowledge from their existing experience of medical research. Nevertheless, across the whole sample, experience of medical research appeared to be associated with a greater desire to learn more (figure 2). In multivariate analysis, the most powerful predictor of interest in learning more about medicines safety was currently good/very good overall knowledge of medicines R\&D, which perhaps emphasises the importance of developing good approaches to informing the public about this area. Good knowledge of medicines R\&D was also found to be related to experience of medical research participation (see online supplementary data 5). Therefore, as more people become involved in medical research, this may help to increase overall public knowledge and interest in this area. Current knowledge of medicines R\&D may therefore have been low as at most $10 \%$ of respondents reported experience of medical research (table 1).

\section{Discussion of methodology}

The survey used a robust quota sampling method, ensuring that a good cross-section of the adult population in each country was studied. Nevertheless, apart from Poland, the included countries were mainly in Western Europe, and so the findings are not generalisable across all of Europe.

This was an online survey, completed by those who were familiar with the internet and had chosen to join online research panels. Internet penetration in 2013 was $83 \%$ in France, $86 \%$ in Germany, $90 \%$ in the UK, $75 \%$ in Spain, $65 \%$ in Poland and $59 \%$ in Italy. ${ }^{30}$ Therefore, in France, Germany and the UK, it is likely that the survey panel was broadly representative of the population; however, in Spain, Poland and Italy, the digital divide may have impacted on sample representativeness.

Lay definitions for all aspects of medicines $\mathrm{R} \& \mathrm{D}$ were developed and tested using cognitive interviewing. ${ }^{17}$ Nevertheless, as the survey was administered online, it was impossible to identify how participants were interpreting the definitions on a wider basis.

\section{CONCLUSIONS AND IMPLICATIONS}

This study has a number of implications both for the EUPATI project and beyond.
First, public interest in medicines R\&D was greater than public knowledge, which suggests that attempts to increase public knowledge will be welcomed. However, there are limits to public interest because at most $60 \%$ of respondents were interested in learning more about a particular aspect of medicines R\&D. Therefore, EUPATI may have a role in stimulating the public's interest in medicines R\&D. Second, having previous experience of medical research appeared to either increase both current knowledge or interest in learning more about medicines $\mathrm{R} \& \mathrm{D}$ or may mean that a person approached is more likely to consent to participate in medical research. However, raising awareness of medicines R\&D should be focused on fostering informed choice regarding participation and involvement rather than on increasing trial recruitment. Third, existing patterns of trial recruitment may impact on knowledge and future interest in medicines $\mathrm{R} \& \mathrm{D}$, that is, there are groups who are currently under-represented in clinical trials who may be very interested in learning more, such as women and older people. Fourth, patients' and the public's awareness of many aspects of medicines R\&D may be so low that they may not feel they have a need to learn more.

Finally, without increasing patients' and the public's knowledge and awareness of their roles in the medicines $\mathrm{R} \& \mathrm{D}$ process, it will be challenging to facilitate their more active involvement in the medicines R\&D process.

\section{Author affiliations}

${ }^{1}$ Public Programmes Team, Central Manchester University Hospitals NHS Foundation Trust \& University of Manchester, Manchester Academic Health Science Centre, Manchester, UK

${ }^{2}$ Public Health Evidence and Insights, Global Public Affairs, Novo Nordisk, A/S, Copenhagen, Denmark

${ }^{3}$ Institute of Brain, Behaviour and Mental Health, University of Manchester, Manchester, UK

${ }^{4}$ Focus on the Patient, Medical Platforms UK, GlaxoSmithKline, London, UK ${ }^{5}$ Department of Research and International Affairs, Dutch Genetic Alliance (VSOP), Soest, The Netherlands

Acknowledgements The authors would like to acknowledge all other members of the EUPATI needs assessment work package who contributed to this work. They are as follows: Kate Dack (University of Manchester), Celine Lewis (Genetic Alliance UK), Mary Uhlenhopp (Amgen), Anne Marie Dillon (Genzyme), Mike Hardman (AstraZeneca) and Barbara Haake (Association of Research Base Pharmaceutical Companies -vfa). They would also like to acknowledge the contribution and comments on this survey from members of the EUPATI content development work package, including Per Spindler (University of Copenhagen), Niels Westergaard (University of Copenhagen), Matthew May (DIA). They would also like to thank Karen Facey and Wolf See for their comments on this manuscript. They would like to thank ICM Research who conducted the fieldwork, The European Federation of Pharmaceutical Industries and Associations (EFPIA) for financial contribution to the survey and the EUPATI translation panel for their support when checking the conceptual translations within the questionnaire. Finally, they would like to thank all of those who completed the survey.

Contributors SP was the project manager for the needs assessment work package and led the design and administration of the survey. BS was the lead for the needs assessment work package. She contributed to the design of the survey and its administration and also to drafts of the paper. KaW and CM-J were the pharmaceutical industry lead and deputy leads, respectively, for the needs assessment work package. They also contributed to the design of the survey and its administration and to drafts of the paper. S-GT was the project 
assistant and assisted in the design and implementation of the survey. She also contributed to drafts of the paper. KiW was a member of the needs assessment work package team and contributed to the design and implementation of the survey and also to drafts of the paper.

Funding The study was funded by the Innovative Medicines Initiative (IMI), which is a collaboration between the European Commission and EFPIA (European Federation of Pharmaceutical Industries and Associations), whose members are listed here (http://www.patientsacademy.eu/index.php/en/ about-eupati). EUPATI is funded by the Innovative Medicines Initiative Joint Undertaking under grant agreement number 115334, resources of which are composed of financial contribution from the European Union's Seventh Framework Programme (FP7/2007-2013) and in kind and financial contributions by EFPIA companies.

Competing interests KaW is employed by GlaxoSmithKline and CM-J is employed by Novo Nordisk.

Ethics approval University of Manchester Research Ethics Committee.

Provenance and peer review Not commissioned; externally peer reviewed.

Data sharing statement Raw anonymised survey data and coded survey data are available from SP (email: suzanne.parsons@cmft.nhs.uk) and BS (email: bella.starling@cmft.nhs.uk) for all countries.

Open Access This is an Open Access article distributed in accordance with the Creative Commons Attribution Non Commercial (CC BY-NC 4.0) license, which permits others to distribute, remix, adapt, build upon this work noncommercially, and license their derivative works on different terms, provided the original work is properly cited and the use is non-commercial. See: http:// creativecommons.org/licenses/by-nc/4.0/

\section{REFERENCES}

1. Coulter A. Patient engagement-what works? J Ambul Care Manage 2012;35:80-9.

2. Coulter A, Askham J, Parsons S. Where are the patients in decision making about their own care. WHO Regional Office for Europe, 2008:1-14.

3. Boote J, Wong R, Booth A. Talking the talk or walking the walk? A bibliometric review of the literature on public involvement in health research published between 1995 and 2009. Health Expect 2012;18:44-57.

4. Grogan K. Pharma optimistic about future, worried about reputation. Pharma Times online. http://www.pharmatimes.com/mobile/14-0613/pharma_optimistic_about_future_worried_about_reputation.aspx? $r=1$ (13 June 2014) (accessed 8 Dec 2014).

5. Smits $E$, Boon $W$. The role of users in innovation in the pharmaceutical industry. Drug Discov Today 2008;13;353-9.

6. Harrison C. Patent watch-dangling from the patent cliff. Nat Rev Drug Discov 2013:12:14-15.

7. Moors E, Cohen AF, Schellekens H. Towards a sustainable system of drug development. Drug Discov Today 2014;19:1711-20.

8. Patient Partner website-http://www.patientpartner-europe.eu/en/ home (accessed 5 Dec 2014).

9. Hemminki E, Toiviainen HK, Vuorenkoshi L. Co-operation between patient organisations and the drug industry in Finland. Soc Sci Med 2010;70;1171-5.

10. Ipsos public affairs. Reputation snapshot for the pharmaceutical sector. Ipsos Mori, 2012. http://www.ipsos.com/public-affairs/sites/
www.ipsos.com.public-affairs/files/Pharma\%20Reputation\% 20Snapshot\%20-\%20INTL.pdf (accessed 8 Dec 2014).

11. PricewaterhouseCoopers' Health Research Institute. Recapturing the vision-restoring trust in the pharmaceutical industry by translating expectations into action. PricewaterhouseCoopers, 2006. http://www pwc.com/en_GX/gx/pharma-life-sciences/pdf/recapturing-the-vision_ exsummary final.pdf (accessed 8 Dec 2014).

12. Mansell P. Survey finds low awareness of clinical research as core NHS activity. 22-5-2012. http://www.pharmatimes.com/Article/1205-22/Survey finds low awareness of clinical_research_as_core NHS_activity.aspx (accessed 8 Dec 2014).

13. Welcome Trust. Medical research and the public-Welcome Trust monitor findings. Welcome Trust, 2013. http://www.wellcome.ac.uk stellent/groups/corporatesite/@msh_grants/documents/web_ document/wtp052592.pdf (accessed 8 Dec 2014).

14. Patients academy website. http://www.patientsacademy.eu (accessed 8 Dec 2014).

15. Eurobarometer. Europeans and their languages. Brussels: European Commission, 2012. http://ec.europa.eu/public_opinion/archives/ebs/ ebs_386_en.pdf (accessed 8 Dec 2014)

16. ICM research website. http://www.icmresearch.com (accessed 8 Dec 2014).

17. Willis GB. Cognitive interviewing: a tool for improving questionnaire design. London: Sage, 2005

18. Bland JM. Statistic's notes@ Cronbach's alpha. BMJ 1997;314: 572.

19. Jeremic V, Bulajic M, Martic M, et al. An evaluation of European countries' health systems through distance based analysis. Hippokratia 2012;16:170-4.

20. Radojicic Z, Jeremic V. Quantity or quality: what matters more in ranking higher education institutions. Curr Sci 2012;103: 158-62.

21. Age profiles of European countries-Eurostat website. epp.eurostat. ec.europa.eu/portal/page/portal/statistics/search database (accessed 8 Dec 2014)

22. Science media centre-evidence to select committee on clinical trials. http://www.sciencemediacentre.org/wp-content/uploads/ 2014/03/SMC-Evidence-on-clinical-trials.pdf (accessed 8 Dec 2014).

23. MHRA's webpage on increasing patients and the public's knowledge of regulation. http://www.mhra.gov.uk/safetyinformation/ Generalsafetyinformationandadvice/Adviceandinformationforconsumers/ Mymedicinefromlaboratorytopharmacyshelf/index.htm (accessed $8 \mathrm{Dec}$ 2014).

24. Leroy $\mathrm{T}$, Christophe V, Penel N, et al. Factual understanding of randomised clinical trials: a multi-center case control study in cancer patients. Invest New Drugs 2011;29:700-5.

25. Patient involvement in drug development-from theory to reality. http://www.patientsacademy.eu/index.php/en/news/press-area/pressreleases/361-patient-involvement-in-industry-r-d-from-theory-toreality (accessed 9 Dec 2014)

26. Kim AM, Tingen $C$, Woodruff $T$. Sex bias in trials and treatments must end Nature 2012:465:668-9.

27. Bartlam B, Crome P, Lally F, et al. The views of older people and carers on participation in clinical trials: the PREDICT Study. $J$ Clin Invest 2012;2:327-36.

28. Jolie A. My medical choice. http://www.nytimes.com/2013/05/14/ opinion/my-medical-choice.html? $r=0$ (accessed 9 Dec 2014).

29. Wang K, Hunt K, Nazareth I, et al. Do men consult less than women? An analysis of routinely collected UK general practice data BMJ Open 2013;3:e003320.

30. Internet World Stats: European Internet Usage Statistics. Internet World Stats 2014 June. http://www.internetworldstats.com/stats4.htm (accessed 8 Dec 2014). 